Check for updates

Cite this: RSC Adv., 2019, 9, 13122

\title{
Experimental and theoretical study for $\mathrm{CO}_{2}$ activation and chemical fixation with epoxides $\uparrow$
}

\author{
Jinwei Gao, (D) ab Liuyi Li, (DD ${ }^{\mathrm{b}}$ Caiyan Cui, ${ }^{\mathrm{b}}$ Muhammad Asad Ziaee, \\ Yaqiong Gong, (D) ${ }^{a}$ Rongjian Sa*c and Hong Zhong ${ }^{\star a b}$
}

The synthesis of five-membered cyclic carbonates via catalytic cycloaddition reaction of $\mathrm{CO}_{2}$ with epoxides is considered to be an effective technology for alleviation of the energy crisis and global warming. Various commercial organic bases and ionic salts were used as catalysts, while the relationship of catalytic activity and compound structure has been seldom explored. Herein, a facilely obtained binary catalytic system based on triethylamine/NBu $3 \mathrm{Br}$ was developed for $\mathrm{CO}_{2}$ activation and chemical fixation. The highly efficient catalytic system showed outstanding conversion and above $99 \%$ selectivity under metal-free mild reaction conditions $\left(100{ }^{\circ} \mathrm{C}, 1 \mathrm{~atm}\right)$ in one hour. The detailed process of $\mathrm{CO}_{2}$ activation and chemical fixation was investigated at the molecular level by a series of experiments and theoretical calculation, which provided a mode for the design and synthesis of a highly efficient catalytic system for conversion of $\mathrm{CO}_{2}$ under mild conditions.

Received 21st December 2018 Accepted 24th April 2019

DOI: $10.1039 / c 8 r a 10475 a$

rsc.li/rsc-advances zeolites, ionic liquids, carbon nitride and so on. ${ }^{23-32}$ Though most catalysts were used to activate epoxide by a metal ion or hydrogen bond center, the effect of $\mathrm{CO}_{2}$ activity on the reaction efficiency has rarely been studied deeply.

$\mathrm{CO}_{2}$ is the highest oxidation state of carbon, and it is thermodynamically stable and kinetically inert, which will consequently hinder the development of efficient catalysts that achieve $\mathrm{CO}_{2}$ activation and subsequently its functionalization..$^{23,33,34}$ Thus the activation of $\mathrm{CO}_{2}$ is pivotal for its effective conversion. The introduce/use of Lewis basic species and transition metal system have been highly considered, while the detailed $\mathrm{CO}_{2}$ activation process was unclear, ${ }^{35-38}$ so developing a catalytic system that provides molecular level insight for $\mathrm{CO}_{2}$ activation process is still highly desired. Taking the aforementioned concerns into account, we propose to explore a new catalytic system that can activate and convert $\mathrm{CO}_{2}$ with epoxides under mild conditions, and serve as an ideal mold for providing a detailed mechanistic understanding of $\mathrm{CO}_{2}$ activation and fixation process.

Herein, a simple and efficient binary catalytic system based on organobase/ $\mathrm{NBu}_{4} \mathrm{Br}$ was developed for $\mathrm{CO}_{2}$ cycloaddition reaction with epoxides under metal-free mild conditions. It was found that the synergistic effect between two components in this new catalytic system promote the cycloaddition reaction occur under atmospheric pressure during a short time period of 1 hour. Moreover, the relationship of catalytic activity and catalyst structure was investigated at molecular level by a series of experiments and theoretical calculation, which could not only offer in-depth understanding of the reaction mechanism but also provide a theoretical basis for the effect of triethylamine $\left(\mathrm{NEt}_{3}\right)$ in activating $\mathrm{CO}_{2}$ and promoting the reaction process.
${ }^{a}$ College of Science, North University of China, Taiyuan, Shanxi 030051, P. R. China ${ }^{b}$ State Key Laboratory of Structural Chemistry, Fujian Institute of Research on the Structure of Matter, Chinese Academy of Sciences, Fuzhou, Fujian 350002, China. E-mail: zhonghong@ffirsm.ac.cn

'Institute of Oceanography, Ocean College, Fujian Provincial Key Laboratory of Information Processing and Intelligent Control, Minjiang University, Fuzhou, Fujian 350108, China. E-mail: rjsa@mju.edu.cn

$\dagger$ Electronic supplementary information (ESI) available. See DOI: $10.1039 / \mathrm{c} 8 \mathrm{ra} 10475 \mathrm{a}$ 


\section{Results and discussion}

To understand the effects of the counter anions on the catalytic activity, the catalytic cycloaddition reaction of $\mathrm{CO}_{2}$ with epoxides were initially investigated in the presence of $0.5 \mathrm{~mL} \mathrm{NEt}{ }_{3}$. As shown in Table $1, \mathrm{NBu}_{4} \mathrm{Br}$ afforded a full conversion of 2 -(chloromethyl)oxirane to 4-(chloromethyl)-1,3-dioxolan-2-one under 1.0 atm. $\mathrm{CO}_{2}$ at $100{ }^{\circ} \mathrm{C}$ for $1.0 \mathrm{~h}$ (entry 1 ), and the catalytic conversion showed unconspicuous change when the $\mathrm{NBu}_{4} \mathrm{Br}$ was replaced by $\mathrm{NBu}_{4} \mathrm{Cl}, \mathrm{NBu}_{4} \mathrm{I}$, respectively (entries 2-3). Notably, the yield of 2(chloromethyl)oxirane to 4-(chloromethyl)-1,3-dioxolan-2-one decreased significantly when $\mathrm{NBu}_{4} \mathrm{PF}_{6}$ was used under the same condition, which is probably due to the weakest nucleophilicity of $\mathrm{PF}_{6}{ }^{-}$in selected $\mathrm{Cl}^{-}, \mathrm{Br}^{-}, \mathrm{I}^{-}$, and $\mathrm{PF}_{6}{ }^{-}$, suggesting the counter anions play a dominant role in cycloaddition reaction of $\mathrm{CO}_{2}$ with epoxides. ${ }^{39}$ When the common organic base $\mathrm{NEt}_{3}$ was used alone under the same condition, $36 \%$ yield of 2 -(chloromethyl)oxirane to 4-(chloromethyl)-1,3-dioxolan-2-one was obtained (entry 6), indicating that $\mathrm{NEt}_{3}$ can activate $\mathrm{CO}_{2}$ in this reaction. ${ }^{40}$ Based on the above results, the high efficiency of the binary system is probably attributed to a synergistic effect between $\mathrm{NBu}_{4} \mathrm{Br}$ and $\mathrm{NEt}_{3}$ during the catalytic conversion of $\mathrm{CO}_{2}$ with epoxides to cyclic carbonates.

Additionally, the influence of the basicity on the conversion of 2-(chloromethyl)oxirane was investigated in the presence of $\mathrm{NBu}_{4} \mathrm{Br}$ with various organic bases at $100{ }^{\circ} \mathrm{C}$ for $1 \mathrm{~h}$ (Fig. $1 \mathrm{a}$ and b). As shown in Fig. 1b, the yield of 4-(chloromethyl)-1,3dioxolan-2-one greatly related to the basicity of organic bases, and $\mathrm{NEt}_{3}$ gave rise to the highest conversion of 2-(chloromethyl) oxirane to corresponding product due to its strongest alkalinity and minimum steric hindrance. The activities of organic bases decreased sharply from $99 \%$ to 92 and $63 \%$ when the pKa decrease from 18.8 to 10.2, respectively. As reported previously, the base was weaker, the $\Delta G$ of this reaction was lower, ${ }^{41}$ so the basicity order might be DIPEA $>\mathrm{NEt}_{3}>$ TBA $>$ TMEDA $>$ MIm $>$ Py $>$ DMBA. However, the catalytic activity order of the organic bases is not in strict accordance with the established $\mathrm{pKa}$, that was $\mathrm{NEt}_{3}>$ TBA $>$ Py $>$ TMEDA $>$ MIm $>$ DIPEA $>$ DMBA, which indicates that the basicity of the organic bases is one important factor for promoting catalytic activity, but the steric-hindrance also play a role in this catalytic reaction. ${ }^{23}$

Table 1 Catalyst screening for the conversion of $\mathrm{CO}_{2}$ with 2-(chloromethyl)oxirane $^{a}$

\begin{tabular}{lllll}
\hline Entry & Catalyst & Time (h) & Yield $^{b}(\%)$ & Select. $^{b}(\%)$ \\
\hline 1 & $\mathrm{NBu}_{4} \mathrm{Br}+\mathrm{NEt}_{3}$ & 1 & 99 & $>99$ \\
2 & $\mathrm{NBu}_{4} \mathrm{Cl}+\mathrm{NEt}_{3}$ & 1 & 97 & $>99$ \\
3 & $\mathrm{NBu}_{4} \mathrm{I}+\mathrm{NEt}_{3}$ & 1 & 96 & $>99$ \\
4 & $\mathrm{NBu}_{4} \mathrm{PF}_{6}+\mathrm{NEt}_{3}$ & 1 & 43 & $>99$ \\
5 & $\mathrm{NBu}_{4} \mathrm{Br}$ & 1 & 34 & $>99$ \\
6 & $\mathrm{NEt}_{3}$ & 1 & 36 & $>99$
\end{tabular}

${ }^{a}$ Reaction conditions: 2-(chloromethyl)oxirane (12.8 mmol), $\mathrm{NBu}_{4} \mathrm{X}(\mathrm{X}$ $\left.=\mathrm{Br}^{-}, \mathrm{Cl}^{-}, \mathrm{I}^{-}, \mathrm{PF}_{6}{ }^{-}\right)(0.06 \mathrm{mmol}), \mathrm{NEt}_{3}(0.5 \mathrm{~mL}), \mathrm{CO}_{2}(1 \mathrm{~atm}), 100{ }^{\circ} \mathrm{C}$. ${ }^{b}$ Yield was determined by GC and ${ }^{1} \mathrm{H}$ NMR. The possibility of byproduct was 3-chloro-1,2-propanediol.
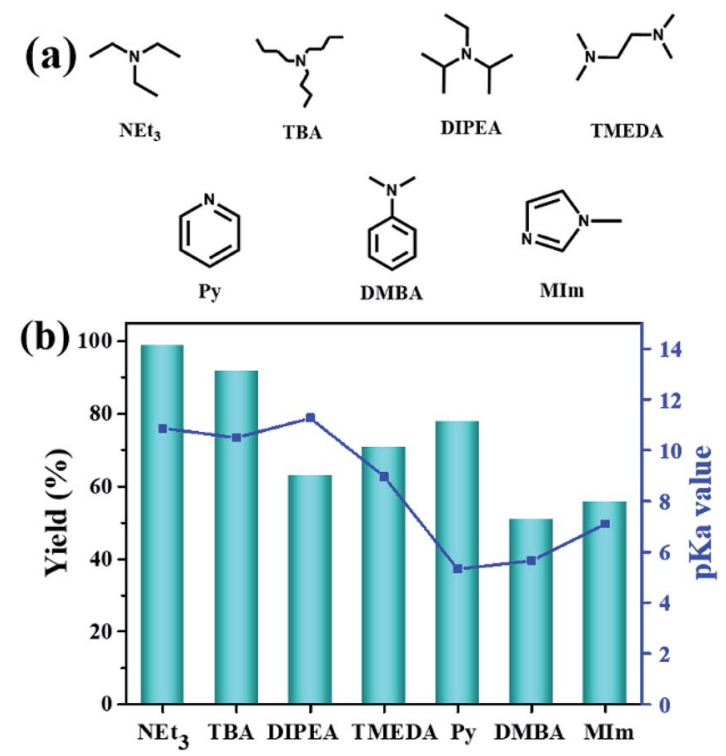

Fig. 1 Organic bases structures (a); the effect of organic bases on the yield of cyclic carbonate (b). pKa value of the conjugated acid in water which was obtained from the U.S. National Library of Medicine database. ${ }^{42}$ Reaction conditions: 2-(chloromethyl)oxirane $(12.8 \mathrm{mmol}$ ), $\mathrm{NBu}_{4} \mathrm{Br}(0.06 \mathrm{mmol})$, organic base $(0.5 \mathrm{~mL}), \mathrm{CO}_{2}(1 \mathrm{~atm}), 100{ }^{\circ} \mathrm{C}, 1 \mathrm{~h}$. The possibility of by-product was 3-chloro-1,2-propanediol.

The dependence of the cycloaddition reaction of $\mathrm{CO}_{2}$ and 2(chloromethyl)oxirane on temperature is shown in Fig. 2a. The results indicated that the activity of this catalytic system is highly dependent on the reaction temperature. In the lower temperature region $\left(25\right.$ to $50{ }^{\circ} \mathrm{C}$ ), the yield of 4 -(chloromethyl)-
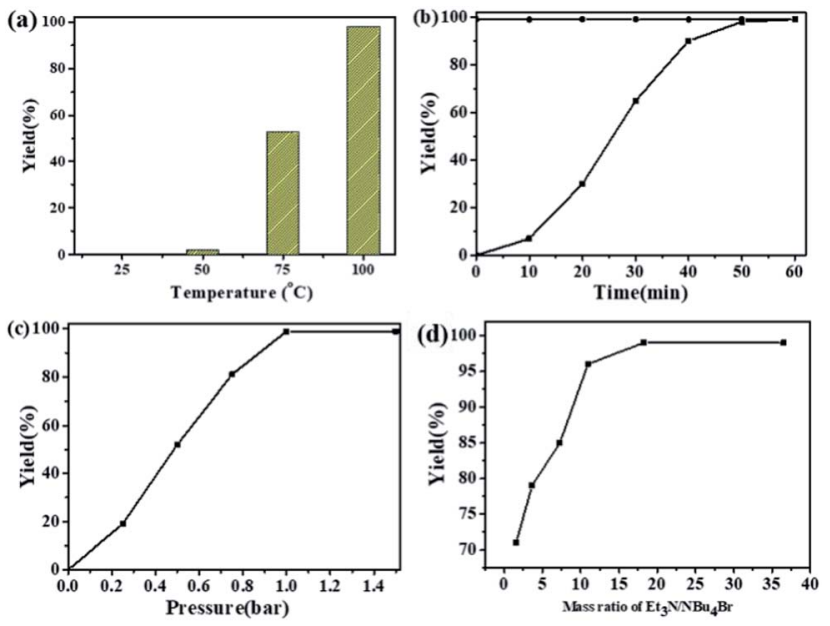

Fig. 2 Effects of different reaction parameters. (a) Effects of reaction temperature, conditions: 2-(chloromethyl)oxirane $(12.8 \mathrm{mmol})$, $\mathrm{NBu}_{4} \mathrm{Br}(0.06 \mathrm{mmol}), \mathrm{NEt}_{3}(0.5 \mathrm{~mL}), \mathrm{CO}_{2}(1 \mathrm{~atm}), 1 \mathrm{~h}$. (b) Effects of reaction time, conditions: 2-(chloromethyl)oxirane $(12.8 \mathrm{mmol}$ ), $\mathrm{NBu}_{4} \mathrm{Br}(0.06 \mathrm{mmol}), \mathrm{NEt}_{3}(0.5 \mathrm{~mL}), \mathrm{CO}_{2}(1 \mathrm{~atm}), 100{ }^{\circ} \mathrm{C}$. (c) Effects of $\mathrm{CO}_{2}$ pressure, conditions: 2-(chloromethyl)oxirane $(12.8 \mathrm{mmol}$ ), $\mathrm{NBu}_{4} \mathrm{Br}(0.06 \mathrm{mmol}), \mathrm{NEt}_{3}(0.5 \mathrm{~mL}), 100^{\circ} \mathrm{C}, 1 \mathrm{~h}$. (d) Effects of mass ratio of $\mathrm{NEt}_{3} / \mathrm{NBu}_{4} \mathrm{Br}$, conditions: 2-(chloromethyl)oxirane $(12.8 \mathrm{mmol}$ ), $\mathrm{NBu}_{4} \mathrm{Br}(0.06 \mathrm{mmol}), \mathrm{CO}_{2}(1 \mathrm{~atm}), 100{ }^{\circ} \mathrm{C}, 1 \mathrm{~h}$. The possibility of byproduct was 3-chloro-1,2-propanediol. 
1,3-dioxolan-2-one increases slowly with increasing temperature. A further increase in temperature from 50 to $100{ }^{\circ} \mathrm{C}$ has significant effects on the 2-(chloromethyl)oxirane conversion, and gave the target product in $99 \%$ GC yield at $100{ }^{\circ} \mathrm{C}$ for $1 \mathrm{~h}$.

The kinetic curve for catalytic conversion of $\mathrm{CO}_{2}$ into cyclic carbonates was also investigated in the presence of $\mathrm{NEt}_{3} /$ $\mathrm{NBu}_{4} \mathrm{Br}$ at $100{ }^{\circ} \mathrm{C}$. As shown in Fig. 2b, the yield of 4(chloromethyl)-1,3-dioxolan-2-one increased rapidly in the first 40 min and then went up slowly. The complete consumption of 2-(chloromethyl)oxirane and synchronous formation of the desired product was achieved in $1 \mathrm{~h}$. It should mentioned that the selectivity remains above $99 \%$ in the entire catalytic process. It could be obviously seen that the reaction pressure showed a great effect on the cycloaddition reaction (Fig. 2c). With the increase of $\mathrm{CO}_{2}$ from 0.25 to 1 atm, the 4-(chloromethyl)-1,3dioxolan-2-one yield increases from 20 to $99 \%$. A further increase in the $\mathrm{CO}_{2}$ pressure from 1 to $1.5 \mathrm{~atm}$ results in a same level in 2-(chloromethyl)oxirane conversion. A similar effect of $\mathrm{CO}_{2}$ pressure on catalytic activity was observed in other related catalytic systems. ${ }^{\mathbf{4 3}, 44}$

The influence of $\mathrm{NEt}_{3}$ to $\mathrm{NBu}_{4} \mathrm{Br}$ ratio on the yield of 4(chloromethyl)-1,3-dioxolan-2-one was also investigated at $100{ }^{\circ} \mathrm{C}$ for $1 \mathrm{~h}$ with fixed $\mathrm{NBu}_{4} \mathrm{Br}(0.06 \mathrm{mmol})$. As shown in Fig. 2d, when the ratio of $\mathrm{NEt}_{3}$ to $\mathrm{NBu}_{4} \mathrm{Br}$ increases from 1.6 to 18.2, the 4-(chloromethyl)-1,3-dioxolan-2-one yield increased rapidly. Then the 2 -(chloromethyl)oxirane conversion stayed almost constant when ratio of $\mathrm{NEt}_{3}$ to $\mathrm{NBu}_{4} \mathrm{Br}$ increased further.

The excellent catalytic activity encouraged us to further explore the generality of the catalytic system, and several expoxides with different steric and electronic characters were tested. The results show that the various diverse epoxides were converted to the corresponding cyclic carbonates in high yields and excellent selective by this effective catalytic system (Table 2 ). The complete conversion of 2-(chloromethyl)oxirane is attributed to the presence of electron-withdrawing $-\mathrm{CH}_{2} \mathrm{Cl}$ group (entry 1), which facilitates nucleophilic attack of halide anions during the ring opening of the epoxide. ${ }^{45,46}$ The catalytic system is still effective for the epoxides with long alkyl carbon chain, such as 2-butyloxirane, 2-(ethoxymethyl)oxirane and 2-((allyloxy)methyl)oxirane (entries 2-4). The reactivity of epoxides with aromatic substituent is similar to that of long alkyl carbon chain (entries 5, 6). Interestingly, the complete conversion of $2,2^{\prime}$-(((propane-2,2-diylbis(4,1-phenylene))bis(oxy)) bis(methylene))bis(oxirane) into $4,4^{\prime}$-(((propane-2,2-diylbis(4,1phenylene))bis(oxy))bis(methylene))bis(1,3-dioxolan-2-one) could be achieved in $18 \mathrm{~h}$ (entry 7 ).

To further understand the underlying principles of $\mathrm{CO}_{2}$ activation, the computation by the DFT (M06-2X) calculations was studied. Preliminary calculations indicated no involvement of $\mathrm{NBu}_{4}{ }^{+}$cation (Fig. S1 in ESI $\dagger$ ), which was consequently neglected from the elaborate calculations reported herein. ${ }^{47}$ With bromide as catalyst (Fig. 3), the ring opening through the attack of a nucleophile on epoxide and $\mathrm{CO}_{2}$ addition takes place simultaneously in ${ }^{\mathrm{a}} \mathrm{TS} 1$, which is considered to be the ratedetermining step with a free energy of $22.3 \mathrm{kcal} \mathrm{mol}^{-1}$. Subsequently, this reaction tended to undergo the carbonate ringclosure step ( $\left.{ }^{\mathrm{a}} \mathrm{TS} 2\right)$ has the energy of $10.8 \mathrm{kcal} \mathrm{mol}^{-1}$ compared to the reactants. This is consistent with the inefficient reaction under the mild experimental conditions.

The efficiency of the reaction is promoted significantly when $\mathrm{NEt}_{3}$ is introduced as the catalyst in addition to the system. To gain further insight into the synergetic catalytic role played by $\mathrm{NEt}_{3}$ and $\mathrm{NBu}_{4} \mathrm{Br}$, more detailed calculations were carried out.

Table 2 Cycloaddition of $\mathrm{CO}_{2}$ to various expoxides catalyzed by triethylamine $/ \mathrm{NBu}_{4} \mathrm{Br}^{a}$

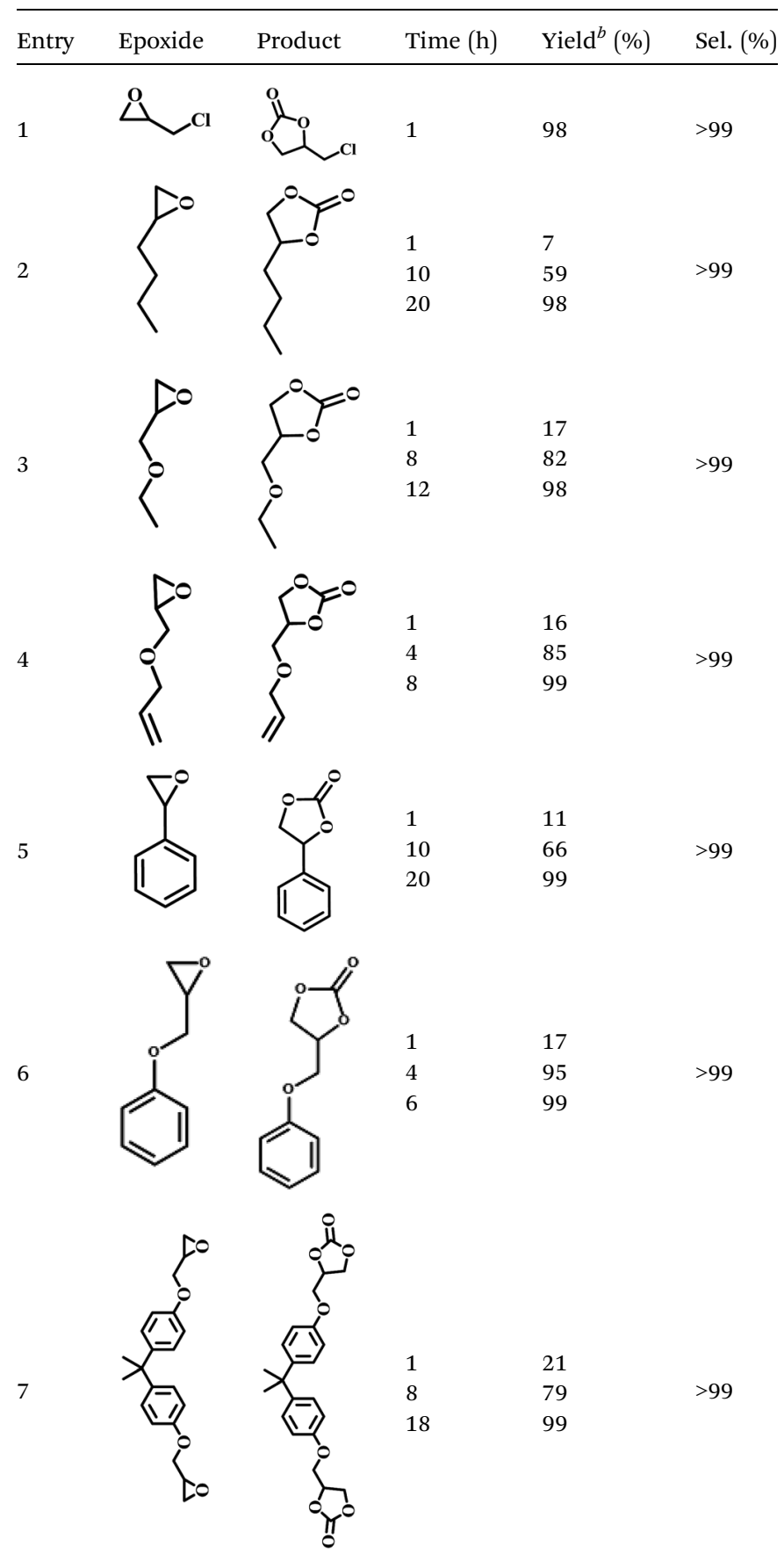

${ }^{a}$ Reaction conditions: epoxide $(12.8 \mathrm{mmol}), \mathrm{NBu}_{4} \mathrm{Br}(0.06 \mathrm{mmol}), \mathrm{NEt}_{3}$ $(0.5 \mathrm{~mL}), \mathrm{CO}_{2}(1 \mathrm{~atm}), 100{ }^{\circ} \mathrm{C} .{ }^{b}$ Yield was determined by GC and ${ }^{1} \mathrm{H}$ NMR. The possibility of by-products were corresponding diols. 


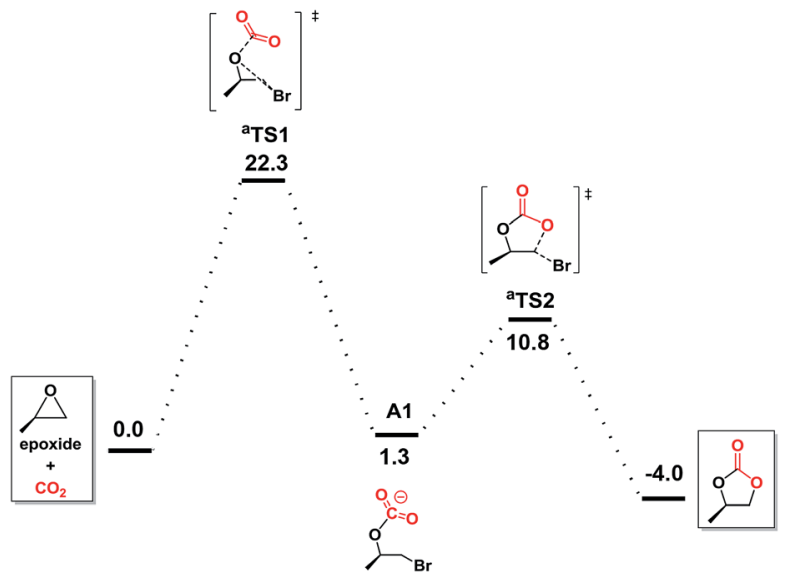

Fig. 3 Free energy profiles for carbonate formation with bromine as catalyst in gas-phase.

When the reaction was calculated in $\mathrm{NEt}_{3}$ solution, there different mechanisms were revealed (Fig. 4). The bromidecatalyzed process (black energy profile shown in Fig. 4) in $\mathrm{NEt}_{3}$ solution shows the same transition states and intermediates as in gas-phase. But the energy barrier of rate-determining step is $31.1 \mathrm{kcal} \mathrm{mol}^{-1}$, which is $8.8 \mathrm{kcal} \mathrm{mol}^{-1}$ larger this procedure without $\mathrm{NEt}_{3}$ solvent. Also the carbonate ring-closure step ( $\left.{ }^{\mathrm{a}} \mathrm{TS} 2\right)$ in $\mathrm{NEt}_{3}$ solution has an energy of $18.2 \mathrm{kcal} \mathrm{mol}^{-1}$, which is $7.4 \mathrm{kcal} \mathrm{mol}^{-1}$ larger than bromide-catalyzed process in gas. For comparison, we also calculated the reaction with $\mathrm{NEt}_{3}$ as catalyst in the absence of bromide (red profile). The $\mathrm{NEt}_{3}$-catalyzed epoxide ring-opening procedure has a high energy barrier ( ${ }^{\mathrm{b}} \mathrm{TS} 1,42.4 \mathrm{kcal} \mathrm{mol}^{-1}$, red profile in Fig. 4), which is $11.3 \mathrm{kcal} \mathrm{mol}^{-1}$ larger than bromide-catalyzed transition state in $\mathrm{NEt}_{3}$ solution. Afterwards, the $\mathrm{CO}_{2}$ addition step to form ${ }^{\mathrm{b}} \mathrm{TS} 2$ has an energy of $46.0 \mathrm{kcal} \mathrm{mol}^{-1}$ relative to the energy of the reactants. Finally, this mechanism of ring-closure process may undergo a ${ }^{b}$ TS3 transition states, which has an energy of $44.7 \mathrm{kcal} \mathrm{mol}^{-1}$ above the reactants. However, the energy barrier of $42.4 \mathrm{kcal} \mathrm{mol}^{-1}$ is quite high and consistent with a sluggish reaction and unable to take place under mild experimental conditions ${ }^{48}$ indicating that $\mathrm{NEt}_{3}$ does not merely act as

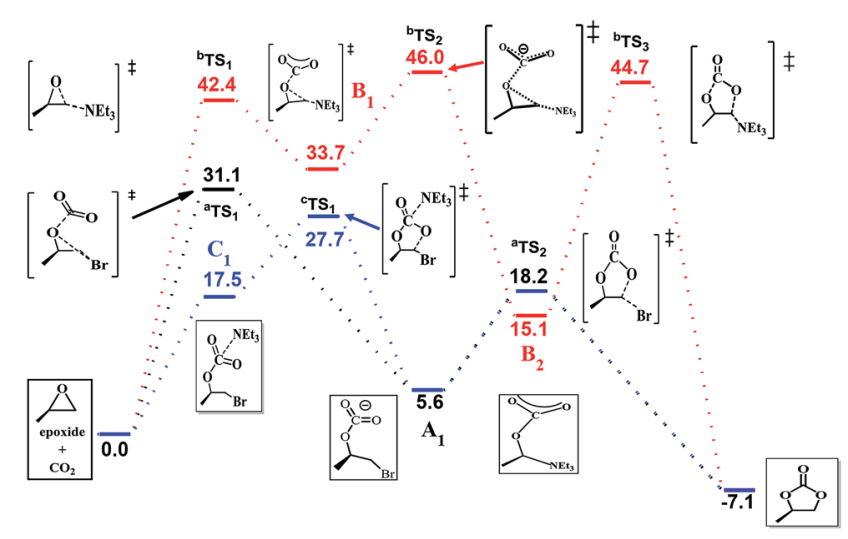

Fig. 4 Free energy profiles of three different mechanisms in $\mathrm{NEt}_{3}$. a solvent but also influences the course of the reaction. Thus, the mechanism when $\mathrm{NEt}_{3}$ participation tends to a bromine and $\mathrm{NEt}_{3}$ jointly catalyzed process (blue profile shown in Fig. 4), a new intermediate $\mathrm{C}_{1}$ appears, resulting from the $\mathrm{CO}_{2}$ addition upon interaction with $\mathrm{NEt}_{3}$ and bromine. This rate-determining step presented no transition states and has an energy of $17.5 \mathrm{kcal} \mathrm{mol}^{-1}$ the above reactants, $4.8 \mathrm{kcal} \mathrm{mol}^{-1}$ energy favorable than pure bromine-catalyzed process in gas-phase, $13.8 \mathrm{kcal} \mathrm{mol}^{-1}$ decrease than bromine-catalyzed procedure in $\mathrm{NEt}_{3}$ solvent, which allows the reaction to be performed under mild conditions. A potential energy surfaces scan calculation based on $\mathrm{C}_{1}$ intermediate validates transition states nonexistent (Fig. S3 in ESI†े). It is conceivable that the ringopening of epoxide and $\mathrm{CO}_{2}$ addition might undergo synchronously with two catalysts. Afterwards, ring-closure takes place through ${ }^{\mathrm{C}} \mathrm{TS} 1 . \mathrm{NEt}_{3}$ then dissociates from the reacting system, which reverts to $A_{1}$ and evolves to product through ${ }^{\mathrm{a}} \mathrm{TS} 2$ with a free energy of $27.7 \mathrm{kcal} \mathrm{mol}^{-1}$ above the reactants. The calculated rate constant is $1.850 \times 10^{-3} \mathrm{~s}^{-1}$ at $373 \mathrm{~K}$. Then the corresponding half-life is ten minute, which accord with the experimental data. The intermediate of $\mathrm{A}_{1}$ with $\mathrm{C}_{1}$ were selected to compare the structure changes in reaction, the $\mathrm{C}-\mathrm{O}$ bond of $\mathrm{CO}_{2}$ change slightly as shown in Fig. $\mathrm{S} 4, \uparrow$ while the $\mathrm{C}-\mathrm{O}$ bond between $\mathrm{C}$ atom of $\mathrm{CO}_{2}$ moiety and $\mathrm{O}$ atom of epoxide moiety decreases from $1.46 \AA$ to $1.43 \AA$, then the interaction between $\mathrm{CO}_{2}$ and epoxide moieties enhanced with $\mathrm{NEt}_{3}$ as solution and catalyst. Moreover, the Mulliken charge of carbon atom of $\mathrm{CO}_{2}$ moiety decreases from 0.3 to 0.07 when compared $\mathrm{C}_{1}$ with $\mathrm{A}_{1}$. Therefore, the bond length and charge analysis suggest that the lone pair electron of nitrogen in $\mathrm{NEt}_{3}$ stabilized the formation of $\mathrm{C}_{1}$ and ${ }^{\mathrm{c}} \mathrm{TS} 1$.

Overall, a plausible mechanism for triethylamine-promoted catalytic conversion of $\mathrm{CO}_{2}$ into cyclic carbonates has been proposed based on the aforementioned results (Fig. 5). First, the epoxide ring opens through nucleophilic attack on the less sterically hindered $\beta$-carbon atom by $\mathrm{Br}^{-}$to produce an alkoxide ion, and simultaneously $\mathrm{CO}_{2}$ is activated by $\mathrm{NEt}_{3}$ via electrostatic interaction to form the carbamate salt. Then a new intermediate $\mathrm{C}_{1}$ is produced resulting from the nucleophilic attack on carbamate salt by alkoxide ion. Finally, cyclic carbonate is produced by following intramolecular ring-closure reaction of $\mathrm{C}_{1}$.

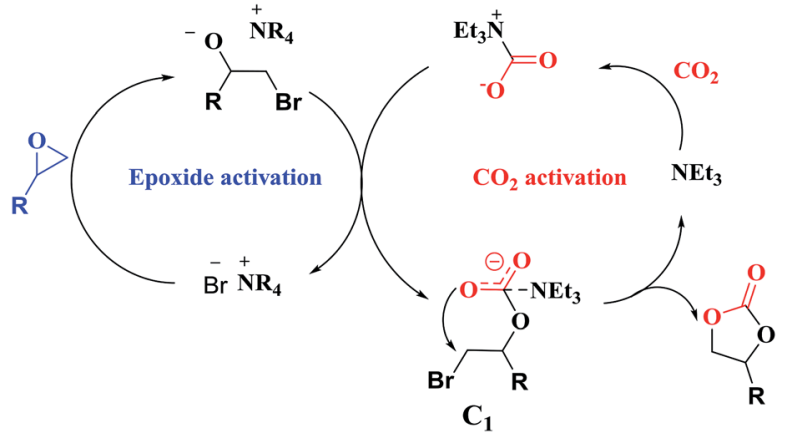

Fig. 5 Proposed reaction pathway for cyclic carbonate formation catalyzed by $\mathrm{NEt}_{3}$ and $\mathrm{NBu}_{4} \mathrm{Br}$. 


\section{Conclusions}

An efficient binary catalytic system containing triethylamine and $\mathrm{NBu}_{4} \mathrm{Br}$ was screened for catalytic conversion of $\mathrm{CO}_{2}$ and epoxides into cyclic carbonates under metal-free mild conditions. Especially, $\mathrm{NEt}_{3}$ could activate $\mathrm{CO}_{2}$ via electrostatic interaction and remarkably reduce the reaction energy to promote the reaction in the catalytic system. This work not only presents a simple and useful route for $\mathrm{CO}_{2}$ chemical fixation into high-value chemicals, but provides a detailed mechanistic understanding of $\mathrm{CO}_{2}$ activation and fixation process.

\section{Experimental}

\section{General}

Chemicals including $\mathrm{NEt}_{3}, \mathrm{NBu}_{4} \mathrm{Br}, \mathrm{NBu}_{4} \mathrm{Cl}, \mathrm{NBu}_{4} \mathrm{I}, \mathrm{NBu}_{4} \mathrm{PF}_{6}$, epoxides and $\mathrm{CO}_{2}$ are commercially available and used directly without further purification. Gas chromatography (GC) was performed on a Shimadzu GC-2014 equipped with a capillary column (RTX-5, $30 \mathrm{~m} \times 0.25 \mu \mathrm{m})$ using a flame ionization detector.

\section{Typical catalytic reaction}

The cycloaddition reaction was carried out by magnetic stirring, trimethylamine $(0.5 \mathrm{ml}), \mathrm{NBu}_{4} \mathrm{Br}(0.06 \mathrm{mmol})$ and 2 -(chloromethyl)oxirane $(12.8 \mathrm{mmol})$ were added into a reactor at room temperature. Then, the reactor was sealed and purged with $\mathrm{CO}_{2}$ to remove air. $\mathrm{CO}_{2}$ was introduced into the reactor and the pressure was adjusted to $1 \mathrm{~atm}$ at room temperature. The reactor was placed into pre-heated oil bath and temperature was maintained at $100{ }^{\circ} \mathrm{C}$. After the reaction was completed, the reactor was cooled to $0{ }^{\circ} \mathrm{C}$ in ice-water bath, and then the excess of $\mathrm{CO}_{2}$ was carefully vented. The mixture was diluted with ethyl acetate. The conversion of epoxide and yield of cyclic carbonate were determined by gas chromatography (Shimadzu GC-2014, a flame ionization detector) and ${ }^{1} \mathrm{H}$ NMR.

\section{Computational details}

The M06-2X functional ${ }^{49}$ was employed in this article to perform all the calculations. Our structure optimizations were as follows. In $\mathrm{NBu}_{4} \mathrm{Br}$ involved reaction, only gas-phase calculations were performed. For carbonate formation with bromine as catalyst, the structures were firstly optimized base on the level of $6-31+G(d, p)$ in gas-phase, then the solvent structure optimizations were carried out based on gas-phase results. As for the rest of other structure optimizations, the calculations were performed in solvent. Vibrational frequency analyses at the same basis sets were used on all optimized structures in order to characterize stationary points as local minima or transition states. Furthermore, the intrinsic reaction coordinate (IRC) calculations at the same level have been applied to validate that transition states connect appropriate reactants and products. The Gibbs free energy were further calculated by single-point energy calculations using $\mathrm{M} 02-2 \mathrm{X} / 6-311+\mathrm{G}(\mathrm{d}, \mathrm{p})$ method on previously $6-31+\mathrm{G}(\mathrm{d}, \mathrm{p})$ structures and thermal corrections at 298.15 K and 1 atm. No conformational sampling calculations were performed in this work. The continuum SMD model ${ }^{50}$ was applied. The Gaussian 09 package ${ }^{51}$ was used for all of our calculations in $\mathrm{NEt}_{3}$ solvent.

\section{Conflicts of interest}

There are no conflicts to declare.

\section{Acknowledgements}

This work was financially supported by the National Natural Science Foundation of China (21603228 and 21671039) and Natural Science Foundation of Fujian Province (2015J01038), State Key Laboratory of Structural Chemistry and Program for Innovative Research Team in Science and Technology in Fujian Province University (IRTSTFJ) and the Open Project Program of the State Key Laboratory of Photocatalysis on Energy and Environment (SKLPEE-KF201813).

\section{Notes and references}

1 F. D. Bobbink, D. Vasilyev, M. Hulla, S. Chamam, F. Menoud, G. Laurenczy, S. Katsyuba and P. J. Dyson, ACS Catal., 2018, 8, 2589-2594.

2 B. B. Lu, W. Jiang, J. Yang, Y. Y. Liu and J. F. Ma, ACS Appl. Mater. Interfaces, 2017, 9, 39441-39449.

3 A. Buonerba, A. D. Nisi, A. Grassi, S. Milione, C. Capacchione, S. Vagin and B. Rieger, Catal. Sci. Technol., 2015, 5, 118-123.

4 Q. L. Qian, J. J. Zhang, M. Cui and B. X. Han, Nat. Commun., 2016, 7, 11481.

5 L. G. Ding, B. J. Yao, W. L. Jiang, J. T. Li, Q. J. Fu, Y. A. Li, Z. H. Liu, J. P. Ma and Y. B. Dong, Inorg. Chem., 2017, 56, 2337-2344.

6 C. Feng, X. L. Cao, L. G. Zhang, C. Y. Guo, N. Akram and J. D. Wang, RSC Adv., 2018, 8, 9192-9201.

7 E. Fazekas, G. S. Nichol, M. P. Shaver and J. A. Garden, Dalton Trans., 2018, 47, 13106-13112.

8 D. H. Lan, H. T. Wang, L. Chen, C. T. Au and S. F. Yin, Carbon, 2016, 100, 81-89.

9 L. Wang, R. L. Zhang, Q. X. Han, C. Xu, W. M. Chen, H. Yang, G. S. Gao, W. W. Qin and W. S. Liu, Green Chem., 2018, 20, 5311-5317.

10 M. H. Anthofer, M. E. Wilhelm, M. Cokoja, M. Drees, W. A. Herrmann and F. E. Kühn, ChemCatChem, 2015, 7, 94-98.

11 L. Martinez-Rodriguez, J. Otalora Garmilla and A. W. Kleij, ChemSusChem, 2016, 9, 749-755.

12 J. K. Qiu, Y. L. Zhao, Z. Y. Li, H. Y. Wang, M. H. Fan and J. J. Wang, ChemSusChem, 2017, 10, 1120-1127.

13 Z. J. Guo, Q. W. Jiang, Y. M. Shi, J. Li, X. N. Yang, W. Hou, Y. Zhou and J. Wang, ACS Catal., 2017, 7, 6770-6780.

14 M. R. Li, M. C. Zhang, T. J. Yue, X. B. Lu and W. M. Ren, RSC Adv., 2018, 8, 39182-39186.

15 L. Wang, G. Y. Zhang, K. Kodama and T. Hirose, Green Chem., 2016, 18, 1229-1233. 
16 C. Maeda, T. Taniguchi, K. Ogawa and T. Ema, Angew. Chem., Int. Ed., 2015, 54, 134-138.

17 H. L. Parker, J. Sherwood, A. J. Hunt and J. H. Clark, ACS Sustainable Chem. Eng., 2014, 2, 1739-1742.

18 A. H. Tamboli, A. A. Chaugule and H. Kim, Fuel, 2016, 184, 233-241.

19 Z. Z. Yang, L. N. He, Y. N. Zhao, B. Li and B. Yu, Energy Environ. Sci., 2011, 4, 3971-3975.

20 J. Q. Wang and Y. G. Zhang, ACS Catal., 2016, 6, 4871-4876.

21 L. Guo, L. L. Deng, X. C. Jin, Y. R. Wang and H. Z. Wang, RSC Adv., 2018, 8, 26554-26562.

22 C. K. Johannes Steinbauer, R. Ludwig and T. Werner, ACS Sustainable Chem. Eng., 2018, 6, 10778-10788.

23 J. Sun, W. G. Cheng, Z. F. Yang, J. Q. Wang, T. T. Xu, J. Y. Xin and S. J. Zhang, Green Chem., 2014, 16, 3071-3078.

24 R. C. Luo, Z. Yang, W. Y. Zhang, X. T. Zhou and H. B. Ji, Sci. China: Chem., 2017, 60, 979-989.

25 T. Berestok, P. Guardia, R. F. Du, J. B. Portals, M. Colombo, S. Estrade, F. Peiro, S. L. Brock and A. Cabot, ACS Appl. Mater. Interfaces, 2018, 10, 16041-16048.

26 J. Zhu, P. M. Usov, W. Q. Xu, P. J. Celis-Salazar, S. Y. Lin, M. C. Kessinger, C. Landaverde-Alvarado, M. Cai, A. M. May, C. Slebodnick, D. Zhu, S. D. Senanayake and A. J. Morris, J. Am. Chem. Soc., 2018, 140, 993-1003.

27 K. Zhou, B. Mousavi, Z. X. Luo, S. Phatanasri, S. Chaemchuen and F. Verpoort, J. Mater. Chem. A, 2017, 5, 952-957.

28 J. Y. Hu, J. Ma, H. Z. Liu, Q. L. Qian, C. Xie and B. X. Han, Green Chem., 2018, 20, 2990-2994.

29 X. H. Song, Y. F. Wu, D. H. Pan, F. F. Cai and G. M. Xiao, Mol. Catal., 2017, 436, 228-236.

30 J. Liang, Y. Q. Xie, Q. Wu, X. Y. Wang, T. T. Liu, H. F. Li, Y. B. Huang and R. Cao, Inorg. Chem., 2018, 57, 2584-2593.

31 J. J. Zhu, T. T. Diao, W. Y. Wang, X. L. Xu, X. Y. Sun, S. A. C. Carabineiro and Z. Zhao, Appl. Catal., B, 2017, 219, 92-100.

32 A.-L. Girard, N. Simon, M. Zanatta, S. Marmitt, P. Gonçalves and J. Dupont, Green Chem., 2014, 16, 2815-2825.

33 Q. Liu, L. P. Wu, R. Jackstell and M. Beller, Nat. Commun., 2015, 6, 5933.

34 S. Marmitt and P. F. Goncalves, J. Comput. Chem., 2015, 36, 1322-1333.

35 S. Hayashi, S. Yamazoe, K. Koyasu and T. Tsukuda, Chem.Asian J., 2017, 12, 1635-1640.

36 X. D. Lang and L. N. He, Chem. Rec., 2016, 16, 1337-1352.

37 X. F. Liu, Q. W. Song, S. Zhang and L. N. He, Catal. Today, 2016, 263, 69-74.
38 B. Sarmah and R. Srivastava, Ind. Eng. Chem. Res., 2017, 56, 8202-8215.

39 H. Zhong, Y. Q. Su, X. W. Chen, X. J. Li and R. H. Wang, ChemSusChem, 2017, 10, 4855-4863.

40 L. Wang, G. Zhang, K. Kodama and T. Hirose, Green Chem., 2016, 18, 1229-1233.

41 D. J. Heldebrant, C. R. Yonker, P. G. Jessopc and L. Phan, Energy Environ. Sci., 2008, 1, 487-493.

42 L. Gong and J. S. McCullagh, Rapid Commun. Mass Spectrom., 2014, 28, 339-350.

43 J. Q. Wang, W. G. Cheng, J. Sun, T. Y. Shi, X. P. Zhang and S. J. Zhang, RSC Adv., 2014, 4, 2360-2367.

44 M. S. Liu, L. Liang, X. Li, X. X. Gao and J. M. Sun, Green Chem., 2016, 18, 2851-2863.

45 Z. Z. Yang, Y. F. Zhao, G. P. Ji, H. Y. Zhang, B. Yu, X. Gao and Z. M. Liu, Green Chem., 2014, 16, 3724-3728.

46 J. Liang, R. P. Chen, X. Y. Wang, T. T. Liu, X. S. Wang, Y. B. Huang and R. Cao, Chem. Sci., 2017, 8, 1570-1575.

47 C. J. Whiteoak, A. Nova, F. Maseras and A. W. Kleij, ChemSusChem, 2012, 5, 2032-2038.

48 W. Cho, M. S. Shin, S. Hwang, H. Kim, M. Kim, J. G. Kim and Y. Kim, J. Ind. Eng. Chem., 2016, 44, 210-215.

49 Y. Zhao and D. G. Truhlar, Theor. Chem. Acc., 2008, 120, 215241.

50 A. V. Marenich, C. J. Cramer and D. G. Truhlar, J. Phys. Chem. B, 2009, 113, 6378-6396.

51 M. J. Frisch, G. W. Trucks, H. B. Schlegel, G. E. Scuseria, M. A. Robb, J. R. Cheeseman, G. Scalmani, V. Barone, G. A. Petersson, H. Nakatsuji, X. Li, M. Caricato, A. Marenich, J. Bloino, B. G. Janesko, R. Gomperts, B. Mennucci, H. P. Hratchian, J. V. Ortiz, A. F. Izmaylov, J. L. Sonnenberg, D. Williams-Young, F. Ding, F. Lipparini, F. Egidi, J. Goings, B. Peng, A. Petrone, T. Henderson, D. Ranasinghe, V. G. Zakrzewski, J. Gao, N. Rega, G. Zheng, W. Liang, M. Hada, M. Ehara, K. Toyota, R. Fukuda, J. Hasegawa, M. Ishida, T. Nakajima, Y. Honda, O. Kitao, H. Nakai, T. Vreven, K. Throssell, J. A. Montgomery Jr, J. E. Peralta, F. Ogliaro, M. Bearpark, J. J. Heyd, E. Brothers, K. N. Kudin, V. N. Staroverov, T. Keith, R. Kobayashi, J. Normand, K. Raghavachari, A. Rendell, J. C. Burant, S. S. Iyengar, J. Tomasi, M. Cossi, J. M. Millam, M. Klene, C. Adamo, R. Cammi, J. W. Ochterski, R. L. Martin, K. Morokuma, O. Farkas, J. B. Foresman, and D. J. Fox, Gaussian 09, Revision E.01, Gaussian, Inc., Wallingford CT, 2016. 